\title{
Do Market Prices Reflect Real Scarcity? Theories and Facts
}

\author{
Adolfo Figueroa ${ }^{a}$

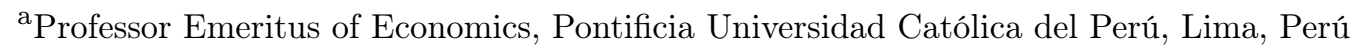 \\ $\bowtie$ afiguer@pucp.edu.pe
}

\begin{abstract}
Do market relative prices reflect real scarcity of resources? If this were so, market prices would provide society with the correct signals about real scarcities. Economics - the science of scarcityhas different answers to this question. Following the principles of current epistemology, the paper reviews three theories of markets: neoclassical, bio-economics, and unified theory, analyzing their assumptions, their derived empirical predictions about the relation between market prices and scarcity, and their validity when confronted against known basic facts. Clarifying misconceptions about the nature and the role of the market mechanism in the functioning of capitalism is the expected contribution of the paper.
\end{abstract}

Article History: Received: 15 April 2019 / Revised: 05 May 2019/ Accepted: 17 May 2019

Keywords: Market institution; Market theory; Market structure; Market competition; Market relative prices; Natural resources; Scarcity; Capitalism.

JEL Classification: D01, D02, D40, D50, P10, Q50

\section{Acknowledgements}

The author wishes to thank Gabriel Rodríguez, Editor, and an anonymous referee, for his valuable comments. 


\section{Introduction}

The market system is one of the fundamental institutions of capitalism. People exchange goods mostly through markets. Do market prices reflect the real scarcities facing society? If this were so, market prices would provide society with the correct signals about real scarcities.

The science of economics - known as the science of scarcity - has different answers to this question, depending on the theoretical approach used. Following the principles of current epistemology, this paper reviews three economic theories of markets, analyzing their assumptions and their empirical predictions about the relation between market prices and scarcity, and confronting them against known basic facts: the neoclassical theory of markets (sections 2-4), the theory of bio-economics (sections 5-6), and the unified theory of capitalism (section 7). Section 8 concludes. Clarifying misconceptions about the nature and the role of the market mechanism in the functioning of capitalism is the expected contribution of the paper.

\section{Neoclassical Theory of Markets}

According to neoclassical economics, the market mechanism has properties that are good for society, among them that market prices reflect society's real scarcities; i.e., market prices provide society with signals of real scarcities.

In science, propositions like this must come from assumptions - i.e., a theory - about the forces underlying real world behavior. In particular, the mechanism mentioned above comes from the neoclassical theory of markets, which assumes that people exchange goods through markets, the rules of which are, first, that exchange is voluntary; second, that people exchange goods guided by self-interest; third, that market participants are endowed with economics assets; and fourth, that people's interactions lead to competition through market prices.

In order to draw empirical inferences from this theory, it is necessary to define a social context in which people interact as described above. The standard model assumes that markets operate under pure competition; i.e., supply and demand conditions, where buyers and sellers are price takers. Capital and labor are the only scarce factors of production, whereas natural resources are abundant. The following theorem summarizes the assumptions and the predictions derived from the standard model.

Theorem 1. The Standard Model of Markets in Neoclassical Theory. If: (1) m goods are produced in society using $n$ factors of production (i.e., there are $m+n$ markets) and society's factor endowments consist of different types of capital and labor, such that none is redundant; (2) markets are Walrasian; (3) markets operate under perfect competition;(4) risk is measurable (i.e., probability distributions of events are known and given); (5) externalities and public goods are ignored; (6) natural resources are redundant factors of production; (7) the market mechanism is able to solve by itself, spontaneously, the system of equations implied by market exchange through demand and supply; and (8) economic activity is represented as a static and short-run process; Then: (A) the market mechanism is able to determine the general equilibrium of prices and quantities exchanged: $m+n-1$ relative prices, the price level, and $m+n$ equilibrium quantities; 
(B) exogenous changes in factor endowments and in the relative scarcity of factors of production lead to changes in market relative prices of goods and factors of production; i.e., relative prices will reflect real scarcities.

Assumption 1 states that for each good and each factor of production there is a corresponding market. Assumptions 2 and 3 state that each market operates under pure competition in the sense that buyers and sellers are price takers - no one has market power to set prices. In each market, equilibrium prices and quantities are determined by the interaction of buyers and sellers; that is, by demand and supply conditions, such that nominal prices change to equalize the quantities demanded and supplied. The implication is that any excess demand situation in a market will not prevail, as it will lead to price increases, which will continue until the market is cleared. Similarly, excess supply leads to price decreases until they eventually clear the market. Markets that clear through changes in fully flexible nominal prices are known as Walrasian markets.

The remaining assumptions can be briefly described as follows. Assumption 4 ensures that the risk of incurring in losses is known, and people's behavior internalize the probability distribution of events (prices and quantities may then refer to average values). Assumption 5 ensures that private costs are the relevant costs, and are thus equal to social costs. Assumption 6 eliminates any influence of natural resources on the economic process; i.e., the economic process is independent of the ecological system. Assumption 7 states that the market mechanism is somehow able to solve the interactions in market exchange, which take the form of a system of equations. Finally, a static economic process implies that the equilibrium values of the endogenous variables (prices and quantities) will remain unchanged as long as the exogenous variables (capital and labor endowments, in this case) also remain unchanged.

How does this abstract market mechanism operate? The market theory assumes that exchange through markets involves a system of equations and that the market mechanism operates as if it were a big computer, able to solve the system of equations. Therefore, knowing the nature of the system of equations to be solved by the fictitious computer will help us to understand the underlying assumption. For each market there are two equations (demand and supply) and two endogenous variables (price and quantity of equilibrium), the solution of which is called partial equilibrium. This is a monetary economy, where people exchange goods using money as means of payments, so one of the markets is money.

Therefore, taking into account the interactions in all markets implies a total of $2 m+2 n$ equations, which are supposed to be sufficient to solve the equilibrium values for prices and quantities; i.e., the general equilibrium. The question is not just counting equations and unknowns, but knowing the assumptions about the ways in which the solution is reached.

A new property of the market mechanism appears in the general equilibrium analysis. Since no one can buy anything unless selling something (the individual budget constraint reflecting the endowments of capital and labor), then, in the aggregate, the total monetary value of purchases must be equal to that of sales. Therefore, an additional equation is necessary to reach the general equilibrium. Moreover, the equation showing the aggregate budget constraint implies the following: if all markets but one have reached equilibrium, the remaining market must necessarily be in equilibrium too-known as Walras's law of markets. Therefore, two equations (demand and

\section{(웅 PUCP}


supply in the redundant market) and two unknowns (price and quantity in the redundant market) may be subtracted from the system; therefore, the market system contains $2 m+2 n-2$ independent equations.

In order to determine the general equilibrium solution, the market model assumes two separate subsystems: real and monetary, where the solution is sequential: the real subsystem is solved first, independently of the latter, which is subsequently solved. The real subsystem determines relative prices and quantities simultaneously. This separation assumes that people are interested in goods; i.e., in real variables alone - they do not suffer from money illusion. If the money market is considered to be composed by a single money market, the real subsystem consists of $m+n-1$ markets. Applying Walras's law to the real subsystem, one market is redundant; therefore, the real subsystem consists of $m+n-2$ markets, with $2 m+2 n-4$ equations, to solve for an equal number of unknowns (quantities and relative prices) in each market. This is the core of the market system equilibrium.

Once the core solution is attained, the rest of the endogenous variables are just obtained by implication. Thus, the remaining equilibrium quantity for the remaining market becomes known. Supply and demand equations for the money market are now determined, and thus the equilibrium values of the price level and quantity of money, including the real quantity of money (real cash balances) are known. The nominal prices also become known by implication. The general equilibrium is thus solved. This solution implies that changes in money supply will affect only the price level, but not the real variables. This is the principle that money is neutral in market exchange.

In this theoretical model, where buyers and sellers are price takers, market prices play a kind of parametric role in the individual behavior of buyers and sellers, which leads to a general equilibrium solution. The market system is thus equivalent to a system of equations. This assumption implies that whatever the market mechanism does in the real world to provide society with prices and quantities, it is equivalent to solving this system of equations.

The market equilibrium conditions imply that firms operate along their corresponding supply curves, which represent their marginal costs; therefore, relative prices will reflect the opportunity cost or social cost of goods. Thus, in the case of two goods and two factors of production, the solution of the market system lies on its production frontier, with full employment in the use of resources (capital and labor); moreover, the market relative price of goods will be tangent to the production frontier curve, and thus equal to the rate of transformation of one good into the other. The higher the slope of the production frontier, showing the opportunity cost of a good, the higher its relative price will be. The equilibrium relative prices of factors of production thus reveal their relative scarcity, given by the derived demand (reflecting factor intensities) associated to the production structure.

This is the nature of the system of equations involved in market exchange that the market mechanism is able to solve. This is result A of Theorem 1. To be sure, Theorem 1 assumes that the market mechanism is able to solve this particular system of equations (assumption 7), that the general equilibrium exists, and it is unique and stable; the theorem does not prove it. It is a theorem in logic (not in mathematics), where propositions are logically derived from the set of 
assumptions of an economic theory.

The market equilibrium conditions - i.e., that the demand and supply curves meet in each market - are unobservable. Their function is to allow the model to generate falsifiable propositions to accept or reject the theoretical model.

Given that the general market equilibrium condition is, by assumption, unique and stable, the method of comparative statics may be used to derive causality relations between endogenous and exogenous variables. These relations will also constitute the empirical predictions of the model, thereby making it falsifiable. This is result B of Theorem 1. The model predicts that the scarcer a factor of production, the higher its relative price, and the higher the relative price of goods that are intensive in the use of that factor, for a given production structure. If facts refute this prediction, then the model is false and must be rejected. The theorem is logically correct, but empirically false. The set of assumptions of the model are proved to be inappropriate to construct a good abstract representation of the real world.

In order to test result $\mathrm{B}$, the model must be operationalized. Researchers must construct a mathematical model with a particular set of equations (the structural equations) aiming at the model's falsification against data from a particular reality. This set of equations must have a particular solution that is unique and stable (the reduced form equations), which in this case must not be assumed, but given mathematical proof. This is to ensure that the particular mathematical model is consistent with the assumptions of the theoretical model and with results $\mathrm{A}$ and $\mathrm{B}$ of Theorem 1, which are observable and thus falsifiable. Thus the operationalization of the theoretical model is mathematical, whereas the testing of the reduced form equations is statistical, using a dataset from the reality under study.

The static model has a set of assumptions that constitute a logical system, free of internal inconsistencies. According to the principles of modern epistemology, whether the assumptions are appropriate or not will be seen in the falsification process of the model. However, the usual practice of economists is not to falsify theories, but to discuss the assumptions. The "Cambridge Controversy" of the 1960s is an example of a controversy about assumptions; of course, it did not lead to the rejection of any theory involved, nor to the progress of economics (Cohen and Harcourt, 2003). Another example is the discussion of the assumption about the real-monetary dichotomy, which was originally criticized by Don Patinkin, but from the perspective of another set of assumptions.

\section{Overpopulation, Dynamic Process, and Imperfect Competition}

Some of the assumptions of Theorem 1 can be relaxed to show the role they play in the results. On assumption 1, consider now that the factor endowments in society are such that there is overpopulation: the marginal productivity of the total labor supply of a given type is zero. Then the market price of this labor would be zero or near zero. However, this solution is socially unviable. A subsistence sector is needed, where workers can make some income from selfemployment, which in turn generates a supply function of labor such that the equilibrium market wage rate will be positive. This is the case of Third World countries, where a capitalist sector

\section{(a) PUCP}


coexists with subsistence sectors, such as the peasant economy operating in marginal agricultural lands and small businesses in urban areas.

Consider a dynamic economic process (relaxing assumption 8). Now physical and human capital are endogenously accumulated in the long run. Assuming that dynamic equilibrium is just the sequence of static equilibrium situations, the market mechanism will generate a general equilibrium solution for prices and quantities in each period; thus, the solution will imply a particular path for each endogenous variable. Under dynamic equilibrium, these paths will remain unchanged as long as the values of the exogenous variables remain unchanged.

In the case of two goods and two factors of production, it follows that the paths lie on the production frontier (full employment equilibrium) in each period; moreover, in each period relative prices are equal to marginal costs. Do relative prices now reflect scarcity? The static solution in period 1 takes place on a particular point along the production frontier, but for each point on the production frontier curve there will exist a particular production frontier in period 2 , and so on; that is, the production frontier in period 1 maps a set of production frontier curves in period 2, which together constitute a grand production frontier in period 2 (the envelope curve), and so on. Hence, choices on a particular point of the production frontier in period 1 lead to a point on the corresponding production frontier in period 2, which in turn leads to a production frontier in period 3, but this path does not necessarily go through the grand frontier curves.

For this to happen, as is well known, two conditions are needed. First, a particular final production structure of society must be chosen in advance as long-run objective. If society does not know where it wants to go, then a given path can hardly be considered the most efficient one. Second, attaining this objective implies reaching the grand frontier curve in each period, which in turn implies a particular path of capital accumulation - known as the von Neumann-Ray theorem or the Turnpike theorem. Therefore, there is no guarantee that the market mechanism solution as a sequence of static equilibrium situations will lead to the grand production frontier in each period, nor that relative prices will reflect marginal costs and thus scarcities. Result A of Theorem 1 holds, but result B does not.

When the market structure is different from perfect competition (i.e., relaxing assumption 3 ), the results are as follows. For monopoly and oligopoly market structures, supply and demand equations in each market are replaced by marginal cost and marginal revenue equations; therefore, the market system consists of the same number of equations and unknowns as in the perfect competition case, and general equilibrium prices and quantities in market exchange will be determined.

However, monopolistic and oligopolistic firms will be price makers. It has been shown that monopoly and oligopoly markets producing homogeneous goods are reducible to a behavior based on marginal costs and marginal revenues. This is the well-known Cournot theorem, a corollary of which shows that the principle can be extended to the case of oligopoly markets producing differentiated goods. Therefore, market prices under imperfect competition will not lie along the marginal cost curve, but above it, along the demand curve; that is, market relative prices of goods will not reflect relative social costs. Relative prices will not be given by the tangent of the production frontier at the mix of goods produced, but by a secant. The derived demand for labor 
will be at a lower level, compared to the competitive firm, for the same nominal wage rate; thus, the equilibrium wage rate will tend to be lower for a given labor supply. In sum, although result A of Theorem 1 holds, result B does not.

\section{The Case of Exhaustible Natural Resources}

Now consider relaxing assumption 6 of Theorem 1: natural resources are not a redundant factor, but are scarce and exhaustible. The standard model of neoclassical economics for the market of exhaustible or non-renewable resources is due to Hotelling (1931). For the sake of exposition, let the term "mineral" (including minerals, oil, and gas) refer to these resources. The assumption is that the owner of a mine faces a tradeoff: the owner can leave the resource in the ground or extract and sell it and then purchase a financial asset with the proceeds; that is, the owner can keep the resource as a physical asset or turn it into a financial asset. Assuming the marginal cost of extraction is nil, the micro equilibrium condition is that the expected price of the mineral as percentage of the current price should be equal to the current interest rate.

Under perfect competition in the mining industry, the market equilibrium condition will be the one indicated above. If the expected mineral price (given) relative to the current price were higher than the interest rate, then today's supply of minerals would decline and today's price will tend to increase, and this would continue until the given expected price relative to the current price has declined to the point that it is equal to the interest rate; the equilibrium price and quantity in today's market would thus be determined. If the expected price relative to the current price were smaller than the interest rate, competition would also lead to market equilibrium.

The prediction of the model is as follows. Once the equilibrium price $\left(p_{0}\right)$ and quantity $\left(Q_{0}\right)$ in today's mineral market has been determined by market competition, the market price will rise over time at a rate that is equal to the interest rate $(r)$; that is, $p_{1}=(1+r) p_{0}$ for the next period. (Assuming that the price level remains unchanged, this relation holds for both nominal and relative prices.) The rate of depletion, which is equal to the quantity supplied $\left(Q_{0}\right)$, will be repeated period after period. Therefore, changes in the interest rate will shift up or down the path of mineral market prices over time. On normative grounds, this is also considered the social optimum depletion rate, known as the Hotelling rule, assuming that the interest rate reflects accurately the individual's subjective rate of future discount.

Models of the neoclassical market theory are rarely tested, as pointed out earlier. However, some testing have been carried out for the market of exhaustible resources. The facts refute Hotelling model's prediction, as follows:

Fact 1. The market prices of exhaustible resources have grown by a rate that is smaller than the relevant interest rate over several decades.

Fact 2. Relaxing some of the assumptions - introducing imperfect competition, a nonzero marginal cost of extraction, and making the expected mineral price dependent on the expected price of close substitutes - have led to new models and new predictions, which are also refuted by facts. These conclusions showing that the Hotelling model, in both the 
original and modified versions, fails to explain the behavior of market prices of exhaustible natural resources (minerals, oil, and gas), are amply reported in the academic literature (e.g., Krautkraemer, 1998; Neumayer, 2000; Kahnna, 2003; Kronenberg, 2008; Livernois, 2009; Chari and Christiano, 2014).

Fact 3. The market relative prices of exhaustible natural resources (relative to price levels) have shown significant fluctuations, with no increasing trends, showing even negative growth rates in the last decades. Moreover, the market price trend of abundant resources with sufficient geological reserves for a thousand years does not differ significantly from the price trend of geologically scarce mineral resources whose ores may be exhausted within decades or a century; furthermore, no canonical model has been developed to explain these fluctuations (Cuddington and Jerrett, 2008; Jacks et al., 2011; Carter et al., 2011; Stuermer, 2018; Henckens et al., 2016).

\section{Market Behavior Under Bio-economics}

According to Earth sciences, the Holocene age has ended, ushering in the new Anthropocene age. Human economic activity is now the major factor influencing the Earth's behavior. This change in ages started around the 1950s, since the end of the World War II, a period in which the capitalist system has experienced rapid economic growth, which still continues, but under rising ecological stress. Bio-economics is a new school seeking to study the economic process under these new ecological conditions.

Bio-economics assumes not only that the economic process and the ecological system are inter-dependent, but that the economic process is entropic. The physical laws of thermodynamics, governing the relations between matter and energy, constitute an essential element of the economic process. Hence, degradation of the biophysical environment-pollution and depletionand its impact back on humans is considered a significant outcome of the economic process.

How would the entropic economic process be reflected in market prices? Nicholas GeorgescuRoegen - the founder of bio-economics - gives the following answer:

Since in both cases there is no such thing as the cost of undoing an irreparable harm [pollution] or reversing an irrevocable depletion, and since no relevant [market] price can be set on avoiding the inconvenience if future generations cannot bid on the choice, we must insist that the measures taken for either purpose should consist of quantitative regulations...Let no one, economist or not, forget that the irresponsible deforestation of numerous mountains took place because 'the price was right' and that it was brought to an end only after quantitative restrictions were introduced (cited in Bonaiuti, 2011, p. 89-90).

The bottom line is that under an entropic economic process market prices cannot reflect the scarcities of nonrenewable resources. There cannot be markets for undoing the irreparable harm 
of pollution (and of climate change), nor for reversing the irrevocable depletion of exhaustible natural resources. Similarly, one can say that there are no markets - and there cannot be - where one can exchange years of old age for years of youth. Human life is also entropic, subject to continuous and irrevocable degradation.

On normative economics, Georgescu-Roegen argued against the Hotelling rule: "We must discard the principle of discounting the future, which has served as the basis for Harold Hotelling's famous study of the economics of the irreplaceable resources and continues to do so. Mankind, as a quasi-immortal entity, cannot discount the future, only a mortal may do so" (cited in Bonaiuti, 2011, p. 113).

On positive grounds, however, the market theory of bio-economics needs to be operationalized through a mathematical model from which the prediction that market prices do not (and cannot) reflect scarcities of mineral resources could be derived, as a falsifiable proposition. A simple and elementary model is now presented to attempt to fill that gap.

Consider a static economic process. There are three markets in the capitalist society: one single final good (which takes the form of total output $Y$ and capital stock $K$ ), non-renewable natural resources (material inputs $N$, such as matter and energy), and labor $(L)$. The technological relations are as follows:

$$
\begin{gathered}
Y_{t}=\min \left\{F\left(K_{t}, L_{t}\right), N_{t} / n\right\} \\
S_{t}=S_{0}-N_{t}=S_{0}-n Y_{t} \\
\Pi_{t}=\Pi_{0}+\pi_{t}=\Pi_{0}+b N_{t}=\Pi_{0}+b n Y_{t}
\end{gathered}
$$

Equation (1) is the production function, which assumes limitational factors; and mineral resources as a factor of production are non-substitutable. Equation (2) shows the depletion rate of mineral resources $\left(N_{t}\right)$, where $S_{0}$ is the given stock of mineral resources on the Earth's crust. Equation (3) in turn shows the pollution rate $\left(\pi_{t}\right)$, which adds to the pollution concentration in the atmosphere $\left(\Pi_{0}\right)$.

Assuming that all markets are Walrasian and operate under perfect competition, the market mechanism can be represented in its finest form. In the industry producing $Y$, firms seek to maximize profits $\left(P^{\prime}\right)$ as follows:

$$
P^{\prime}=Y-w L^{\prime}-p_{2} N-c^{\prime} K^{\prime}, \text { subject to equation (1) }
$$

The market mechanism determines relative prices; hence $p_{2}$ and $w$ indicate the prices of mineral inputs and labor in units of the final output. Symbol $c^{\prime}$ is the capital depreciation rate required to maintain the firms' capital stock constant. Similarly, firms in the mineral industry seek to maximize profits $\left(P^{\prime \prime}\right)$ as follows:

$$
P^{\prime \prime}=p_{2} N-w L^{\prime \prime}-c^{\prime \prime} K^{\prime \prime}
$$

$$
\text { Subject to the production function } N=G\left(K^{\prime \prime}, L^{\prime \prime}\right)
$$

The cost of production of minerals and the production function refer to the extraction activity. Thus, the coefficient $c^{\prime \prime}$ refers to depreciation costs of the investment made by the firms in opening mines. 
The general equilibrium conditions require that the quantities demanded and supplied be equal in each market. Thus,

$$
\begin{gathered}
Y^{d}=Y^{s} \\
N^{d}=N^{s} \\
L^{d}=L^{\prime}+L^{\prime \prime}=L^{s} \\
\left(Y^{d}-Y\right)+p_{2}\left(N^{d}-N^{s}\right)+w\left(L^{d}-L^{s}\right)=0
\end{gathered}
$$

Equations (7)-(9) indicate the equilibrium condition in each market. Equation (10) is derived from the aggregate condition that the value of purchases must be equal to the value of sales. It is the general equilibrium condition, which implies that if two markets are in equilibrium, the third one will necessarily be in equilibrium too (Walras's law). Let the market for the final good be the redundant one. Conditions (8) and (9) then constitute the core of the general equilibrium solution. We can then write the market equilibrium conditions for the mineral resource market and the labor market as follows:

$$
f\left(p_{2}, w ; K^{\prime \prime}\right)=g\left(p_{2}, w ; K^{\prime}\right)
$$

where $f_{1}<0, f_{2}<0, f_{3}>0$, and $g_{1}>0, g_{2}<0, g_{3}>0$

$$
h\left(p_{2}, w ; K\right)=L^{s},
$$

where $K=K^{\prime}+K^{\prime \prime}$ and $h_{1}>0, h_{2}<0, h_{3}>0$

The endogenous variables of the general equilibrium are separated from the exogenous variables ( $K$ and $L$ ) by a semicolon. These two equations have two unknowns ( $p_{2}$ and $w$ ) and the equilibrium values are resolved simultaneously by market competition. These will be the market equilibrium relative prices. Then the equilibrium quantities for both markets $(N$ and $L)$ can be known. Finally, the equilibrium quantity for the residual market $(Y)$ is also determined.

The concept of marginal productivity of capital and labor in the production functionequation (1) - is net of the cost of using mineral resources, which are a limitative factor of production. Therefore, the functions in equations (11) and (12) are differentiable. Moreover, as the mineral industry refers to intermediate goods, the general equilibrium also implies equilibrium in the final good industry in a special way: what this industry spends in buying inputs generates wages and profits there, which return as purchases of the final good; hence, the quantity supplied of the final good will be equal to the quantity demanded.

The exogenous variables of the static process include, in addition to the capital stock $(K)$ and labor supply $\left(L^{s}\right)$, the initial stock of minerals on the Earth's crust $\left(S_{0}\right)$ and the initial concentration of pollution in the atmosphere $\left(\Pi_{0}\right)$. At the equilibrium market prices, the static production process is supposed to be repeated period after period, as long as the exogenous variables remain unchanged. Capital is reproduced through depreciation costs. The real wage rate, assuming it satisfies the subsistence consumption of workers, would also imply the reproduction of labor standards. However, in each period there is depletion $\left(S_{0}-N_{t}\right.$ in the first period, $S_{0}-2 N_{t}$ in the second period, and so on) and more pollution concentration $\left(\Pi_{0}+\pi_{t}\right.$ in the first period, 
$\Pi_{0}+2 \pi_{t}$ in the second period, and so on). Thus, at the given equilibrium market relative price of minerals $\left(p_{2}\right)$, the production process is degraded continuously and irrevocably: the stock of minerals becomes scarcer over time, and so does the clean sky. Thus, market relative prices do not reflect real scarcity.

Changes in the values of the exogenous variables will cause changes in the values of the endogenous variables. This causality relations derive from the reduced form equations of the model (the solution of equations (11) and (12)), which will also constitute the empirical predictions of the model. They will then make the model falsifiable and testable, by confronting them with empirical data. Under imperfect competition, market prices would include monopolistic profits and rents, but the results will not change qualitatively. There is no canonical model of mineral markets, as indicated above; therefore, the model presented here just serves the analytical purpose of illustrating the nature of the market mechanism.

In sum, whereas the market relative prices of mineral resources remain unchanged, mineral resources become scarcer; hence, market relative prices do not measure the scarcity of mineral resources. Therefore, result B of Theorem 1 breaks down. This is so even in the static economic process, in which markets operate in their finest form. Pollution or depletion, whichever comes first, will put an end to the economic process and its shifting to another one. The economic process can be repeated, but not forever. The static process is thus a mirage.

In the economic growth process, the gap between market prices and scarcity will tend to be more pronounced. Total final output $Y$ will increase endogenously over time; then depletion and pollution rates will also rise over time, and so will the scarcity of mineral resources. The model shown above suggests that there is no mechanism whereby $p_{2}$ can increase over time. Economic growth is not ecologically sustainable. The dynamic process is also a mirage.

The entropic economic process is evolutionary: quantitative changes are accompanied by qualitative changes (environmental degradation); i.e., there are threshold values that set limits to the process. Once these are reached, the economic process collapses and switches to another process. The market price mechanism cannot internalize the qualitative changes in the economic process, such as pollution and the depletion of mineral resources, thereby leading to its breakdown. In contrast, a static or dynamic economic process implies mechanical processes, in which the economic process can be repeated forever.

\section{Extraction Costs vs Degradation Costs}

According to the physical laws of thermodynamics, depletion and pollution are irrevocable outcomes of the economic process and are thus independent of the extraction cost of minerals. No matter what the cost of extraction is, the stock of minerals on the Earth's crust can only decline and pollution can only increase. The extraction cost of minerals may affect the rate of extraction (the supply of minerals as inputs per unit of time), which will certainly affect the depletion rate of the initial stock.

Firms in the mining industry internalize only the extraction cost of mineral resources, but not the cost of replenishing the quantity that has been depleted, so as to keep the mineral stock 
unchanged, nor the cost of cleaning pollution, so as to keep the degree of clean skies constant. Mining industry prices pass onto the final goods industry the unit cost of extraction, but not the replenishing costs. Therefore, at the market relative prices, the economic process cannot be repeated period after period. This is so even under a market structure of perfect competition, as shown by the model presented above. The physical laws of thermodynamics cannot be eliminated by market competition.

The neoclassical concept of "market prices are right" refers to social costs equal to private costs, but excluding the environment degradation costs. The extraction cost is finite and changeable, but the environment degradation cost is not. The pollution cost is paid in the form of bad health by the current and future generations; and the depletion cost is paid as lower consumption levels by future generations. However, these environment degradation costs cannot be internalized by the market price system. The current market price of mineral resources is thus subsidized via lower quality of life for current and future generations. The extraction cost of minerals may be reduced through technological change, but no technological change will be able to eliminate the physical laws of thermodynamics.

What about land resources? Assume fixed land resources and land fertility as original and indestructible (the standard assumption); then land will not be subject to depletion. Hence, it will become increasingly scarce by higher demand in the economic growth process. The market relative price of land will then increase. Changes in market prices of this natural resource will thus indicate changes in its scarcity, as neoclassical theory would predict. However, this is a mirage. Land resources are also non-renewable, as soil is subject to depletion in the economic process.

Confusing the extraction cost of minerals with the replenishing cost of the stock of minerals is analytically treating non-renewable resources as renewable (similar to the cost of cutting tress). Indeed, the argument that the cost of extraction in the world mineral industry is falling, and that consequently the price of mineral inputs is also falling, thereby making minerals more abundant, rather than scarcer, runs strong in the media nowadays. Thus, the argument goes, the observed fall of relative prices of minerals in the last decades (as shown above, Fact 3) indicates that the planet's mineral resources are not being depleted; they are increasing!

This argument is surely a fallacy. It is a confusion between supply of minerals and depletion of minerals. Extraction costs and prices of mineral resources have decreased over time and the quantities extracted and supplied have increased. But this does not imply decreasing scarcity. The higher the quantity supplied, the higher the rate of depletion, and the scarcer the resource. The true scarcity of mineral resources - given the stocks in the Earth's crust - will be revealed only towards the end of total exhaustion. It is possible to have long periods of increasing supply of minerals with lower costs and prices because market prices do not provide society with the correct signals of real scarcity.

It is empirically false to say that market prices always reflect scarcity. Neoclassical Theorem 1 underlying this proposition is thus overlooked. As shown above, the neoclassical theorem assumes implicitly economic processes that are mechanical, not entropic. In other words, neoclassical models assume that environmental problems originate in negative externalities or incomplete 
property rights, and propose market-based approaches to environmental protection, such as a Pigouvian tax or Coasian tradeable emission rights in the case of the commons, as summarized in Stavins (2011).

According to bio-economics, although the environmental problem can be seen as a problem of the commons, it is of a different nature. It is not a microeconomic problem of missing markets, which may be solved creating the necessary markets through well-defined property rights. It is a macro-problem, and an evolutionary one, involving the ecological system and the survival of the human species, in which the constraint is given by the laws of thermodynamics. It is not a case of missing markets that may be created, but one where markets cannot exist. What is true for a micro-problem of the commons is not true for the macro-problem.

Indeed, tradable emissions rights do not seem to work well. In fact, rights-based policies have been created to grant private rights to pollute the environment up to a predetermined limit, and allow these rights to be traded. According to economic evaluations, as summarized in Beder (2001), the effect of these measures was reducing costs to the polluting firms rather than creating incentives for reducing environmental degradation, as their empirical effects have not been significant.

Furthermore, mineral-saving technological change will reduce the quantity of mineral resources per unit of output (coefficients $b$ and $n$ in equation (3) above), but it does not imply the possibility of replenishing the stock. It cannot decrease the rate of pollution and depletion either, for total output will increase in the economic growth process. Depletion and pollution can only be controlled through quantitative restrictions, that is, only through collective action or public policies.

Firms in the mineral industry will certainly react to technological changes that are mineralsaving. Expecting that higher prices of minerals will in the long run induce technological innovations that are mineral-saving, these firms have incentives to speculate with mineral prices and avoid rapid increases. The strategy includes the use of lobbies to downplay the significance of environment degradation by financing research centers and think tanks, as many studies have reported. This complex strategy of firms predicts that market prices are manipulated and will not tend to increase over time; that is, market prices do not tend to reflect the scarcity of non-renewable natural resources.

Replenishing costs may also apply to renewable resources (forestry and fisheries), whenever they are overexploited - beyond the biological regeneration period - due to the macro-problem of the commons. In this case, markets cannot exist due to a lack of private incentives, and thus renewable resources are also subject to depletion, which will also have a pollution effect, as in the case of decreasing forestry areas.

If renewable resources are overexploited in the economic process, then economically they have been transformed into non-renewable resources. Then, analytically, there are only non-renewable natural resources in the economic process, and the finding that market prices do not reflect scarcity now applies to natural resources in general. The asymmetry between the two energy sources in the economic process - solar energy and mineral deposits on the Earth's surfacebecomes less significant. 
Therefore, natural resources in general constitute the fundamental scarce factor in the capitalist economic process. In the short run, capital and labor are given and thus operate as constraints, as shown above. However, in the long run capital and labor can be produced with natural resources, but natural resources cannot be produced; hence, goods and the factors of production capital and labor are reducible to quantities of natural resources, which constitute the non-producible, primary factor of production. Therefore, the scarce element of human society in the long run is given by the dowry of natural resources.

It is sometimes argued that the real problem with environment degradation is that Mother Nature has no cashier. According to the previous analysis, even if that were the case, or even if the cashier could be simulated, depletion and pollution would remain irrevocable due precisely to the fact that the very laws of Mother Nature, namely, the laws of thermodynamics, make the economic process entropic and thus evolutionary.

\section{Market Behavior Under the Unified Theory of Capitalism}

The unified theory of capitalism is a more recent endeavor developed by Figueroa (2015, 2017, 2019). It is unified in a double sense. It assumes that the capitalist system is composed by two subsystems - First and Third World countries - and seeks to explain them separately, as partial theories, and then the capitalist system as a whole. It also assumes that the short- and long-run economic process are consistent with each other, by integrating the assumptions of bio-economics into an economic theory about capitalism. The unified theory seeks unity of knowledge, rather than a fragmented one, thus complying with a fundamental epistemological requirement.

The unified theory is thus a modern theory of capitalism based on a modern theory of markets. The basic assumptions on the functioning of the market mechanism are the following:

First, the unified theory assumes that markets operate with Walrasian and non-Walrasian markets. A non-Walrasian market refers to the case where individual incentives are such that, in the aggregate, market equilibrium is reached with excess demand or excess supply. This is the case of labor markets, where full employment equilibrium is socially unviable, as it would affect labor productivity. If workers were always employed irrespective of their performance, then labor productivity would be low. Firms' profit motives lead to labor market equilibrium with excess labor supply as a mechanism to extract effort from workers. This is the well-known efficient wage theory. Other markets where information is incomplete, such as bank credit and insurance, will tend to operate with excess demand.

Under a general equilibrium model, where Walrasian and non-Walrasian markets coexist, it can be shown that the market system will still retain the nature of market exchange regarding equations and unknowns. Consider a static market model that operates under pure competition with $r$ Walrasian markets and $s$ non-Walrasian markets. In a non-Walrasian market, the nominal market prices are exogenous, and only one equation - either demand or supply - is the relevant one.

Therefore, the market system is composed by $r+s$ markets and $2 r+s$ equations, which should be sufficient conditions to determine the unknowns: the equilibrium values of nominal and relative 
prices, the price level, and quantities in each market. Walras's law applies only to the first group, which makes one of the Walrasian markets redundant; hence, the number of markets is $r-1+s$ and the number of independent equations is equal to $2 r-2+s$, which should solve for an equal number of endogenous variables: $r-1+s$ quantities, $r-2$ relative prices, and the price level. This is the core of the market equilibrium, and the solution is simultaneous. Real and monetary variables interact to determine the solution.

Once the core has been resolved, the remaining endogenous variables are obtained by implication. Hence, the equilibrium quantity in the redundant market now becomes known. The relative price in the non-Walrasian markets also become known, as the price level is now known and the nominal prices are exogenously determined. It follows that this relative price does not reflect scarcity, for it was not determined by the interactions of demand and supply. Finally, the nominal prices in the Walrasian markets also become known.

Therefore, when Walrasian and non-Walrasian markets coexist, the market mechanism can still solve by itself the equilibrium prices and quantities - result A of neoclassical Theorem 1. However, result B breaks down; i.e., market relative prices do not reflect the interactions of demand and supply. In the labor market, for example, real wage rates do not measure labor scarcity, as equilibrium with excess labor supply is attained there. Changes in nominal variables (money supply, nominal interest rates) would change relative prices and the employment level, as in the macro-models of Keynesian theory. Money is not neutral.

Second, the unified theory assumes that the market system operates with both perfect and imperfect competition. According to the unified theory, individuals participating in market exchange are endowed with economic and social assets, which are highly concentrated, leading to the existence of power elites (economic and political). These elites are able to exercise their power through the mechanisms of markets and electoral democracy - the basic institutions of capitalism. Therefore, imperfect competition with large firms (as corporate conglomerates, monopolies, and oligopolies) is an essential factor in the functioning of capitalism.

Thirdly, according to biology, human behavior is the result of both nature (genes) and nurture (social influence), which means that human behavior can be controlled and changed. The unified theory assumes that large firms are able to influence market demand conditions by using behavioral engineering techniques - as psychologist B. F. Skinner called them-to control and change human drives and thus the behavior of consumers and workers. Therefore, large firms exercise their economic power through markets, not only as price makers, but as market makers as well. In contrast, the powerless operate under competitive markets, where buyers and sellers are price takers. This is how the market system works.

Large firms are able to follow complex strategies to maximize profits, subject to bearable risk losses, given by their capital stock endowments. The instruments include manipulating market prices; therefore, changes in market prices need not reflect changes in scarcity, but are just part of large firms' profit maximization strategies (together with sales promotion techniques, such as advertisement, price discounts, coupons, and rebates, together with long-run competition through technology innovations). Market prices may change to reflect changes in scarcity, but this is not their only role. Market prices are part of the set of instruments for profit maximization of large

\section{(is) PUCP}


firms. The latter are not only price makers, but also market makers, as mentioned earlier. There is no one-to-one relation between market prices and scarcity.

In sum, the market behavior assumed by the unified theory of capitalism differs from the neoclassical theory in several ways. It still assumes that market exchange is voluntary and guided by self-interest. However, it does not assume that voluntary exchange implies autonomy in the behavior of buyers and sellers. As to endowments, it assumes highly concentrated economic and social assets leading to the existence of power elites, who run the capitalist system through large firms, whereas the powerless small firms are price takers. As to competition, large firms seek profits through strategies, where prices are just one of the means to that end. Hence, price competition is not essential in market behavior, except in small firms.

Additionally, the predictions of this market theory are different. If large firms' main drive is to seek profits through market exchange, and prices are just a means to that end, then price changes may or may not take into account changes in real scarcity in society. Large firms are able to use means other than prices, or together with prices, to attain the profit end. In particular, market price changes do not reflect changes in the scarcity of natural resources, the primary factors of production.

In the long run, large firms' incentives for technological innovation do not seem to combat scarcities either. According to neoclassical economics, innovations are induced by scarcity, namely by price increases, which lead to new technologies that save on the scarce factor. The relative prices of minerals have not been increasing over time, as shown above (Fact 3), and one may say that indeed these price signals are not inducing much mineral resource-saving technological innovation. At the same time, and as also said earlier, the mineral industry has incentives and instruments to oppose the development of those innovations, as they seek to inhibit them precisely by manipulating market prices and using publicity and lobbying to deny that climate change is happening.

Again, large firms have the power to follow their own interests through different instruments, not just prices. Technological innovations are strategies directed to the profit end, which secures the elites' privileged position in society. If innovations lead to saving the scarce factor in society, it would be a side effect. Indeed, some significant innovations do not seem to respond to changes in relative prices. Thus, labor-saving innovations imply higher profits for any given relative price of labor. Hence, large firms will always pursue this type of innovations, independently of changes in real wage rates. Changes in real wage rates will only have short-run effects on employment and profits. Indeed, what we observe over time is the introduction of labor-saving innovations.

Other technological innovations do not seem to respond to changes in relative prices of known factors or goods, but are directed to create new factors or new goods. This is the case of the new digital technology. The profit motive also seems to underlie this type of innovation, for it is unclear whether it is fighting the scarcity of natural resources.

The unified theory also predicts that markets do not operate in the same manner everywhere in the capitalist system. First and Third World markets operate differently. In Third World countries there are not only class differences, but also citizenship differences (a legacy of European colonialism). Market exchange in a society of first- and second-class citizens operates in a different 
way from a socially homogeneous society. Economic elites can exercise their power through markets and electoral democracy at a higher degree in the Third World. Although the market mechanism solves for equilibrium prices and quantities in each type of capitalism, the equations that markets solve are different.

Economic elites run the capitalist system taken as a whole through large firms. The implication of this assumption is that economic elites are price makers and market makers, and thus able to endogenously create scarcities of goods and factors of production. Hence, changes in relative scarcities would be endogenous and could not be the cause of anything - including changes in market prices - for they are not a cause but a consequence of large firms' behavior. Scarcity and market prices are both endogenous and reflect the power elites' strategies to maximize profits.

It is a well-known fact that the top companies producing minerals, gas, and oil in the world markets are giants (including state companies) and concentrate the industry's production and market value. Therefore, market behavior in the industry of non-renewable resources is more likely to conform to the predictions of unified theory models of markets; namely, price is just an instrument of their business strategies. Hence, market prices need not reflect the increasing scarcities of these resources. The predictions of this market theory is consistent with basic facts (Fact 3 above).

Indeed, empirical studies show that the industrial structure under capitalism is very concentrated in large firms, and increasingly so. This is the result of the relative economic advantages of large size. Some recent studies show that this advantage is now playing through the recent innovations in digital technology. In the case of the U.S. economy, in the last three decades the share of employment in large firms (with more than 100 workers) relative to total employment increased from $60 \%$ to $65 \%$; in addition, the revenue share of the top $5 \%$ of firms increased from $57 \%$ to $67 \%$ (Begenau et al., 2018).

In sum, the unified theory of capitalism leads to a modern theory of markets, which can be summarized in the following theorem.

Theorem 2. Modern Theory of the Market System. If: (1) society functions under a capitalist market system; (2) Walrasian and non-Walrasian markets coexist; (3) perfect and imperfect competition coexist, including powerless small firms that are price takers and large firms that exercise market power not only as price makers but also as market makers; (4) risks of losses are measurable and non-measurable, and markets exist for the former but not for the latter; (5) there are externalities, public goods, and the commons; (6) non-renewable resources are limitative factors of production, but markets for depletion and pollution cannot exist; (7) the market mechanism can solve the system of equations implied by market exchange; and (8) economic processes are static, dynamic, or evolutionary; Then: (I) the market mechanism is able to determine the relative prices and the equilibrium quantities for market exchange; (II) market relative prices do not reflect scarcity of non-renewable resources.

These assumptions about the conditions under which the market mechanism works are totally different from those in the neoclassical theory (Theorem 1). The only exception is assumption 7 . Therefore, the results of Theorem 1 cannot be the same, except for result A, which is identical to result I, namely, that under any general equilibrium model, the market mechanism is able to solve 
by itself for the equilibrium prices and quantities. However, result B of Theorem 1 breaks down and is replaced by result II. Market prices do not (and cannot) reflect scarcities of non-renewable resources. This is consistent with facts, as shown above (Fact 3). Therefore, market prices cannot reveal scarcities of final goods either, as non-renewable resources constitute primary factors of production.

Although result II refers only to non-renewable natural resources, it also applies to renewable resources. The reason is that pollution affects not only human health but also natural capital, such as biodiversity, forestry, and fisheries. Market relative prices do not reflect scarcity of natural resources in general.

The potato and fish markets (perishable goods) constitute the exemplar of neoclassical economics, where the prediction is that market prices tend to reflect scarcities of goods. This is indeed consistent with facts. However, it should be noted that these cases correspond to partial and short-run equilibrium analysis. In the general equilibrium analysis, and in the long run, market prices usually fail to provide scarcity signals.

\section{Conclusions}

Economics is known as the science of scarcity. Scarcity of what? Of goods? No, for goods can be produced. Scarcity of factors of production; i.e., capital (physical and human) and labor? No, for these can also be produced. According to bio-economics, the primary factors are natural resources; thus, scarcity in economics must refer to natural resources.

Do market prices reflect scarcity of natural resources? Economic theories of markets concur in predicting the grand theoretical property of the market mechanism: it operates as if it were a big computer, for it is able to solve by itself for the general equilibrium prices and quantities in a capitalist society. This property holds true under different social and economic contexts. It also tends to be consistent with facts.

The market system solution, however, does not lead to the second property commonly attributed to it, namely, that market relative prices reflect scarcities. This property holds true only under very restrictive conditions, as shown in Theorem 1, the standard market model of neoclassical economics. In the latter, market prices play a parametric role in the individual behavior of buyers and sellers regarding the incentives for economizing in the allocation of scarce resources to alternative uses and for introducing innovations that are scarce resource-saving. Facts refute this prediction of the neoclassical theory of markets. Smith's (1937〈1776 ) well-known proposition that individual self-interest leads, in the aggregate, like an invisible hand, to the common good, where the "invisible hand" is the market mechanism, is circumscribed to Theorem 1.

The unified theory is a modern theory of capitalism for the Anthropocene age. Its assumptions include those of bio-economics. It also includes a modern theory of markets, as summarized in Theorem 2, which predicts that the second market property breaks down. There are two reasons for this result, where either one constitutes a sufficient condition. First, markets for the depletion and pollution of non-renewable natural resources cannot exist. Second, capitalism operates with power elites, which exercise their power through markets and electoral democracy- 
the fundamental institutions of capitalism. Economic elites run large firms, corporations, and conglomerates; hence, they are not price takers, but price makers, and market makers as well. Imperfect competition is the dominant form of market structure under capitalism. Market prices are mostly instruments for profit maximization and thus lose their parametric role in individual economic behavior. Thus, the modern market theory is able to explain the paradox that relative prices of non-renewable resources do not increase over time in spite of the ongoing continuous depletion and pollution.

In light of Theorem 2, "market failure" is certainly a misnomer. The main property of the market mechanism - and the only one - is the solution by itself of equilibrium prices and quantities. Analytically, market failure would only mean that the big computer breaks down for some reason. This is what occurs in special circumstances, such as wars and hyperinflations. The observation that, in general, market prices are not chaotic and that they are continuously, systematically, and orderly present in the economic process is consistent with the prediction.

It is necessary to clarify another misconception about the market institution. Income inequality does not reflect market failure either. The market solution of equilibrium prices and quantities is associated with a given distribution of individual endowments of economic and social assets, which imply a particular power structure. The equilibrium prices and quantities will imply a particular income distribution, the concentration of which will depend on the concentration in the individual distribution of endowments. Different individual endowment distributions, implying different power structures and different system of equations, will lead endogenously to different equilibrium prices and quantities and to a different income inequality structure. Regarding income distribution effects, therefore, the market mechanism is blind. In the economic process, the market institution is a mechanism, not an exogenous variable.

The market mechanism just solves the particular equations that the particular power structure of society feeds into the big computer. The power structure operates through the market and the electoral institutions of capitalism. The market mechanism is the servant; the power structure is the master.

The grand property of the market system explains why it coexists with different degrees of state intervention in the economic process, known as mixed economies, under capitalism. The fact that the market system operates under economic systems other than capitalism, such as in today's communist China, is another proof of the empirical validity of the grand property of the market mechanism. In this regard, Polanyi $(2001\langle 1944\rangle)$ was certainly right in considering the market institution as the great transformation element of modern societies.

This paper has given an explanation of the paradox that market relative prices do not tend to reflect the increasing scarcity of natural resources. Indeed, at the current market prices, we humans have lost forever countless non-renewable and also renewable (biodiversity, forestry, and fisheries) natural resources. The current more hazardous human life conditions due to climate change occur with equilibrium market prices. As a result, survival of the human species has been put into significant risk.

It follows that the only way to cope with the increasing scarcity of natural resources and its consequences for the survival of the human species is through quantity control. Electoral

\section{(웅 PUCP}


democracy - the other fundamental institution of capitalism - has already revealed its inability to tackle this daunting task. The economic theory of democracy is able to explain it by showing that the rules of electoral democracy lead to perverse incentives. This result calls for institutional innovations to replace the current electoral democracy for another more direct form of democracy, so as to make quantitative control both effective and efficient.

These conclusions are based on the acceptance of the modern market theory. In science, accepting a theory is always provisional. Research findings of new data sets, better new theories, and higher new epistemologies will undoubtedly lead to a superior knowledge of the real world. This is how science makes progress.

\section{References}

Beder, S. (2001). Trading the Earth: The politics behind tradeable pollution rights. Environmental Liability 9(2), 152-160.

Begenau, J., Farboodi, M., and Veldkamp, L. (2018). Big data in finance and the growth of large firms. Journal of Monetary Economics 97, 71-87.

Bonaiuti, M. (2011). From bioeconomics to degrowth. Georgescu-Roegen's New Economics in eight essays. London, UK: Routledge.

Carter, C., Rausser, G., and Smith, A. (2011). Commodity booms and busts. Annual Review of Resource Economics 3, 87-118.

Chari, V., and Christiano, L. (2014). The optimal extraction of exhaustible resources. Federal Reserve Bank of Minneapolis, Economic Policy Paper 14-5.

Cohen, A., and Harcourt, G. (2003). Whatever happened to the Cambridge capital theory controversies? Journal of Economic Perspectives 17, 199-214.

Cuddington, J., and Jerrett, D. (2008). Super cycles in real metals prices? IMF Staff Papers $55(4), 541-565$.

Figueroa, A. (2015). Growth, employment, inequality, and the environment. Unity of knowledge in economics. New York, NY: Palgrave Macmillan.

Figueroa, A. (2017). Economics of the Anthropocene age. Cham, Switzerland: Palgrave Macmillan Springer.

Figueroa, A. (2019). The quality of society. Essays on the unified theory of capitalism. Cham, Switzerland: Palgrave Macmillan Springer.

Henckens, M., van Ierland, E., Driessen, P., and Worrell, E. (2016). Mineral resources: Geological scarcity, market price trends, and future generations. Resource Policy 49, 102-111.

Hotelling, H. (1931). The economics of exhaustible resources. Journal of Political Economy 39(2), $137-175$.

Kahnna, N. (2003). On the economics of non-renewable resources. In J. Gowdy (Ed.). Economics interactions with other disciplines. Encyclopedia of Life Support Systems. Oxford, UK: Eolss Publishers.

Krautkraemer, J. (1998). Nonrenewable resources scarcity. Journal of Economic Literature 36(4), 2065-2107. 
Kronenberg, T. (2008). Should we worry about the failure of Hotelling rule? Journal of Economic Surveys 22(4), 774-793.

Jacks, D., O'Rourke, K., and Williamson, J. (2011). Commodity price volatility and world market integration since 1700. The Review of Economics and Statistics 93(3), 800-813.

Livernois, J. (2009). On the empirical significance of Hotelling rule. Review of Environmental Economics and Policy 3(1), 22-41.

Neumayer, E. (2000). Scarce or abundant? The economics of natural resources availability. Journal of Economic Surveys 14(3), 307-335.

Polanyi, K. (2001). The great transformation. The political and economic origins of our time. 2nd edition. Boston, MA: Beacon Press. Originally published in 1944.

Smith, A. (1937). An inquire into the nature and causes of the wealth of nations. New York, NY: Random House. Originally published in 1776.

Stavins, R. (2011). The problem of the commons. Still unsettled after 100 years. The American Economic Review 101(1), 141-188.

Stuermer, M. (2018). 150 years of Boom and Bust - What Drives Mineral Commodity Prices. Macroeconomic Dynamics 22, 702-717. 